\title{
Research on Influencing Factors of Web 3D User Experience with Grounded Theory ${ }^{*}$
}

\author{
Jiangping Wan ${ }^{1,2}$, Hui Zhang ${ }^{1}$ \\ ${ }^{1}$ School of Business Administration, South China University of Technology, Guangzhou, China; ${ }^{2}$ Institute of Emerging Industrializa- \\ tion Development South China University of Technology, Guangzhou, China. \\ Email: scutwjp@126.com, shidelan@163.com
}

Received April 26 ${ }^{\text {th }}, 2011$; revised May 29 ${ }^{\text {th }}, 2011$; accepted June $13^{\text {th }}, 2011$.

\begin{abstract}
The influencing factors on Web 3D User Experience are studied for online pavilion of Shanghai World Expo with grounded theory method. We discover the four influencing factors as follow: web site quality, external environmental factor, user internal factor and recommendation, and the influencing factor model of Web $3 D$ user experience is tried to established. We also do case study for the online Guangdong pavilion of Shanghai World Expo in order improve the process to transfer original wonderful, innovative ideas into Web $3 D$ more perfective. Finally, the areas needing further investigation are put forward.
\end{abstract}

Keywords: Web 3D, User Experience, Shanghai World Expo Online, Grounded Theory

\section{Introduction}

The Harvard Business Review ran an article titled "Welcome to the Experience Economy." Pine and Gilmore, who wrote a book by the same name, argue that the entire history of economic progress could be captured as a progression from extracting commodities (agrarian economy), to making goods (industrial economy), to delivering services (service economy), and now, to one of staging experiences (experience economy). The article suggests characteristics of desirable experiences that draw heavily from entertainment and customer service, as well as five principles for designing such experiences: theme the experience, fulfill it in all the details, harmonize the impression with positive cues, eliminate negative cues, and mix in memorabilia [1].

World Expo 2010 was held in Shanghai with virtual reality and other technologies to present the physical Expo on Internet, and can be seen over the world. The influencing factors of Web 3D user experience are studied for online pavilion of Shanghai World Expo with theory grounded method by questionnaire and in-depth interview. This paper is organized as follow: introduction and literature review are in the first, research design, information coding and case study are in following, and

\footnotetext{
*This research was supported by Key Project of Guangdong Province
} Education Office (06JDXM63002). conclusions are in the end.

\section{Literature Review}

Design principles connect the visual design of a visualization with the viewer's perception and cognition of the underlying information the visualization is meant to convey. Identifying and formulating good design principles often requires analyzing the best hand-designed visualizations, examining prior research on the perception and cognition of visualizations, and when necessary, conducting user studies into how visual techniques affect perception and cognition. Given a set of design rules and quantitative evaluation criteria, we can use procedural techniques and/or energy optimization to build automated visualization-design systems [2]. Within a marketing context, a company must find "a powerful point of differentiation through the use of aesthetics to create positive overall customer impressions that depict the multifaceted personality of the company or brand." Substantial attention is devoted to the branding phase during which a symbol is strategically created, conveys a positioning, provides tangible value, and is most effectively managed on a daily basis [3].

With the improvement of user requirement, experience has become "wide spread, wide angle" [4], evolves into a kind of complete experience which formed during the process of users interacting with software products. As 
long as beauty and goodness stress the subjective valuation of a product, both were related to each other. However, the nature of goodness and beauty was found to differ. Goodness depended on both perceived usability and hedonic attributes. Especially after using the skins, perceived usability became a strong determinant of goodness. In contrast, beauty largely depended on identification; a hedonic attribute group, which captures the product's ability to communicate important personal values to relevant others. Perceived usability as well as goodness was affected by experience (i.e., actual usability, usability problems), whereas hedonic attributes and beauty remained stable over time [5]. The simple way to think about what influences experience is to think about the components of a user-product interaction, and what surrounds it [6] (Figure 1).

\section{Research Design}

Ground theory to provide the basic knowledge and procedures needed by persons who are about to embark on their first qualitative research projects and who want to build theory at the substantive level. The main steps of grounded theory are as follow [7]: 1) theoretical sampling; 2) collecting information; 3) coding information, and forming the concepts from information; 4) comparing between data, and between conceptions and between data and conceptions continually; 5) forming theoretical conceptions, and establishing the relationships between conceptions; 6) building theory and judging it.

We encode the collected information including open coding, axial coding, coding selectively. This paper aims at the new form-Online Shanghai World Expo, does exploratory research on the influencing factors of Web 3D user experience with grounded theory.

\subsection{World Expo Review}

In the true sense, the first World Expo is The Great Exhibition, which was hosted in London's Hyde Park in 1851, and its theme is "World Cultural and Industrial

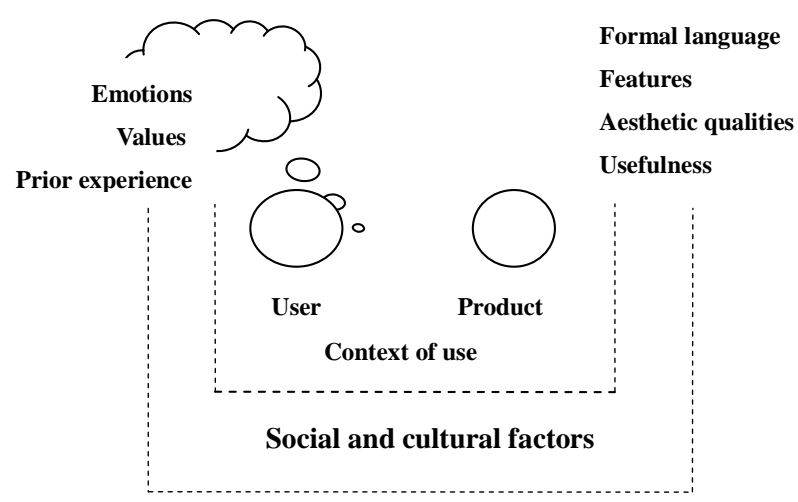

Figure 1. Influences on experience.
Technology". The British illustrated the brilliant achievements after industrial revolution in the World Expo. World Expo through different both ages and countries, presents the new conceptions, new views, new technologies to people, which promote human development. The 2000 Hanover World Expo was hosted in Germany, its theme is "Human, Nature, Technology". The 2005 Aichi World Expo was hosted in Japan, its theme is "Nature's Wisdom". The 2010 World Expo was hosted in Shanghai, China, its theme is "Better City, Better Life".

\subsection{Theoretical Sampling}

We selected the Business Administration bilingual class's third-grade undergraduate students in South China University Technology to investigate. They have the following characteristics: 1) Higher education. 2) Having some basic network knowledge, network as an indispensable tool in life. 3) Open-minded, easily accepting new things, being interested in new things. 4) Sympathetic, paying more attention to life experience.

\subsection{Collecting Information}

In the survey, subjects should be answered the two questions: 1) When you are viewing online World Expo, what aesthetic experience do you have? And why? 2) When you are viewing online World Expo, what unwelcome experience do you have? And why? 40 questionnaires were distributed, and we recovered 40 . We found the related people to interview for something not clear, got the clear expression and tap the potential meaning.

\section{Information Coding}

The original information is analyzed according to three coding: open coding, axial coding, coding selectively. At the last step, we got the influencing factors of Web 3D user experience, and their mechanism of action.

\subsection{Open Coding}

The operating procedure is as follows (Table 1 selects part of the opening coding): 1) To collate the collected original information, label them, and order them, form 1 to 40. 2) To encode the original information step by step, and name, we should try to quote the original words, keep the original meanings of the information, to avoid coding our subjective perspective into them. For example, the user says that "we can see the complete picture of the pavilion clearly from all angles", then we got such coding information - see the complete picture of the pavilion clearly from all angles. 3) To conceptualize the coding content. For example, the sentence "see the complete picture of the pavilion clearly from all angles" is conceptualized, then we got such conception-clearly show- 
Table 1. The example of opening coding.

\begin{tabular}{|c|c|c|}
\hline Original information & Step coding & Conceptualize \\
\hline $\begin{array}{l}\text { We can see the complete picture of the pavilion clearly } \\
\text { from all angles. Before entering the pavilion, you can } \\
\text { choose your favorite mascot as a guide. You will better } \\
\text { understand the details of the exhibition hall if you feel } \\
\text { more interesting, because the guide describes in the form } \\
\text { of voice. It's very easy and convenient. Operation icon is } \\
\text { more obvious and easy to be found. The information of } \\
\text { each pavilion is very rich, which eliminates the trouble of } \\
\text { queuing and painstaking. In addition to the Expo Hall, } \\
\text { there also are many other aspects of the introduction, } \\
\text { which makes people not only feel entertainment and en- } \\
\text { riching the knowledge but also broaden the outlook. }\end{array}$ & $\begin{array}{l}1 \text { see the complete picture of the pavilion clearly from } \\
\text { all angles } \\
2 \text { choose the mascot as a guide, and more interesting } \\
3 \text { the guide describes in the form of voice } \\
4 \text { rich details } \\
5 \text { convenient to find } \\
6 \text { operation icon is more obvious } \\
7 \text { introduction about the others of the World Expo } \\
8 \text { eliminate the trouble of queuing and painstaking } \\
9 \text { not only feel entertainment and enriching the knowl- } \\
\text { edge but also broadening the outlook }\end{array}$ & $\begin{array}{l}1 \text { clearly showing } \\
2 \text { autonomously choosing } \\
3 \text { voice guiding } \\
4 \text { details } \\
5 \text { convenience } \\
6 \text { easy to operate } \\
7 \text { enrich knowledge }\end{array}$ \\
\hline $\begin{array}{l}\text { Most of the online pavilion which is large different from } \\
\text { the actual venues are a virtual multi-animation technol- } \\
\text { ogy, which is slightly less realistic. You will feel very } \\
\text { awkward of moving icons, and the steering is a bit strange } \\
\text { in the venues. Part of the experience in the venues is } \\
\text { humdrum, although some venues are used to reproduce } \\
\text { live-action. The content is very simple, so after reading it, } \\
\text { you will not leave a deep feeling. Due to speed limita- } \\
\text { tions, the picture is cleared very slowly, which greatly } \\
\text { reduces your interest in continuing to read on. }\end{array}$ & $\begin{array}{l}1 \text { large different from the actual venues } \\
2 \text { slightly less realistic } \\
3 \text { mobile icon is felt uncomfortable } \\
4 \text { part of venue is felt humdrum } \\
5 \text { after reading, you can't leave a deep sense } \\
6 \text { speed limits, a slow clear picture, which reducing } \\
\text { your interest in continuing to read on }\end{array}$ & $\begin{array}{l}1 \text { virtual reality } \\
2 \text { humdrum } \\
3 \text { impression } \\
4 \text { speed limit } \\
5 \text { lower interest }\end{array}$ \\
\hline
\end{tabular}

ing. 4) To categorize the concepts. We combine the conceptions which have the same meaning together. For example, beautiful music, high-quality audio and sweet explanation voice, they all mean the good audition effect, so they can be combined together, and form the categorize-Audition effect.

15 categories and 80 conceptions are formed in open coding process with sorting out the information (Table 2).

\subsection{Axial Coding}

The 15 categories and 80 concepts, we discover the hidden relationship between the categories, and reconstruct the dispersed information with deeply analyzing (Table 3).

The similar factors are linked to the same sub-category, for example, integral interface design, virtual reality technology, function implementation and interactive experience have closely relationship with technology, so their category is named "user perceived technical quality".

We totally discover 8 sub-categories. At the same time, the sub-categories which have inherence and causal relations are integrated into the same main-category, for example, positive evaluation and negative evaluation are the outer expression of user experience. We totally discover five main-categories.

\subsection{Coding Selectively}

We have interviewed the project's chief architect and his team. After many mutual discussions, we all think that the external environment is an objective factor, and will impact on the user experience. At the same time, user, a social person, has certain social attribute and maybe have his or her own evaluation according to the previous experience. When something reaches or exceeds the users' evaluation, they will have a better experience and pleasant memories. Combine with project's tender document, the whole process' literature and other documents, we find the influencing factors on Web 3D user experience.

We find external environmental factor and web site quality impact on the user experience through user internal factor. When users' needs or senses are met, they will generate positive assessment, they think they obtain glorious user experience, while users' needs or senses are not met, the negative evaluation is generated, and they obtain dreadful experience. And users may offer suggestion after experiencing, when the suggestions are adopted, the users' internal needs are met, and the web site quality is improved, so the new user experience is generated. When the suggestions are not adopted, users will form new evaluation. That is to say, recommendation reacts on user experience (Figure 2). User internal factor refers to the users' existing need, evaluation standard and expectation before experiencing the Web 3D. External environmental factor is Web 3D operating platform and technical support provided by exterior. In our understanding, Good Web site quality is attributed to the technology what Web 3D developers use to build site, and other supporting conditions. 
Table 2. Open coding.

\begin{tabular}{|c|c|}
\hline Category & Conception \\
\hline A1 integral interface design & $\begin{array}{l}\text { integral design, clear picture, color matching, vivid and visual, font size, illustrated article, balanced proportion } \\
\text { between picture and article, vivid picture and article }\end{array}$ \\
\hline A2 visual effect & $\begin{array}{l}\text { visual impact, high quality video, viewing the whole venue, bright and beautiful, cordial and natural, attraction, } \\
\text { fluent screen }\end{array}$ \\
\hline A3 audible effect & beautiful music, high quality audio, sweet voice explanation \\
\hline A4 virtual reality technology & true simulation, very unreal, aliveness, details are not good enough, inflexible expression \\
\hline A5 information quality & $\begin{array}{l}\text { rich and complete content, clutter content, clear main line, repetitive information, no sense, deeply thinking, } \\
\text { beneficial }\end{array}$ \\
\hline A6 interactive experience & $\begin{array}{l}\text { in-depth experience, influent experience, backward feeling is boring, humanism, interaction, choose freely, } \\
\text { interesting, various scene, changeable perspective, can not fully view content }\end{array}$ \\
\hline A7 desire for knowledge & obtain information, learn knowledge, enrich knowledge, broaden view sight \\
\hline A9 boring and disappoint & $\begin{array}{l}\text { feel too simple, feel immature, confuse, stereotyped style, can not stimulate the desire, simple and boring, have } \\
\text { a great gap with expectation }\end{array}$ \\
\hline A10 function implementation & easy to operate, clear operation icon, limited function, imperfect function, design flaws \\
\hline A11 external environmental factor & network bandwidth, download plug-in \\
\hline A12 saving time and convenience & need not to attend personally, need not to queue, quickly view all venues, quickly search information \\
\hline A13 creative features & creative, features, representative, novel and exciting, challenge \\
\hline A14 extension of the meaning & historical review, jog memory, long-standing reminisce, history feeling \\
\hline A15 user recommendation & offline view, add video with local language style, customer-oriented, development should meet customers' style \\
\hline
\end{tabular}

Table 3. The result of axial coding.

\begin{tabular}{|c|c|c|}
\hline Category & Second Category & Main Category \\
\hline $\begin{array}{l}\text { A1 integral interface design } \\
\text { A4 virtual reality technology } \\
\text { A10 function implementation } \\
\text { A6 interactive experience }\end{array}$ & B1 user perspective technology quality & C1 Web site quality \\
\hline A5 information quality & B2 user perspective information quality & \\
\hline A11 external environmental factor & B3 external environmental factor & $\mathrm{C} 2$ external environmental factor \\
\hline $\begin{array}{l}\text { A2 visual effect } \\
\text { A3 audible effect }\end{array}$ & B4 sense experience & \\
\hline $\begin{array}{l}\text { A7 desire for knowledge } \\
\text { A12 saving time and convenience } \\
\text { A13 creative and featured } \\
\text { A14 extension of the meaning }\end{array}$ & B5 user requirement & C3 user internal factor \\
\hline A8 pleasure and exciting & B6 positive evaluation & C4 user experience \\
\hline A9 boring and disappoint & B7 negative evaluation & \\
\hline A15 user recommendation & B8 user recommendation & C5 user recommendation \\
\hline
\end{tabular}

\subsection{Theoretical Saturation Test}

We take randomly out the collected information again, and don't find new theory. So we consider the theory reaches saturation.

\section{Case Study}

We studied the influencing factors on Web 3D user experience and obtained the four factors as follow: external environmental factor, internal user factor, web site qual- 


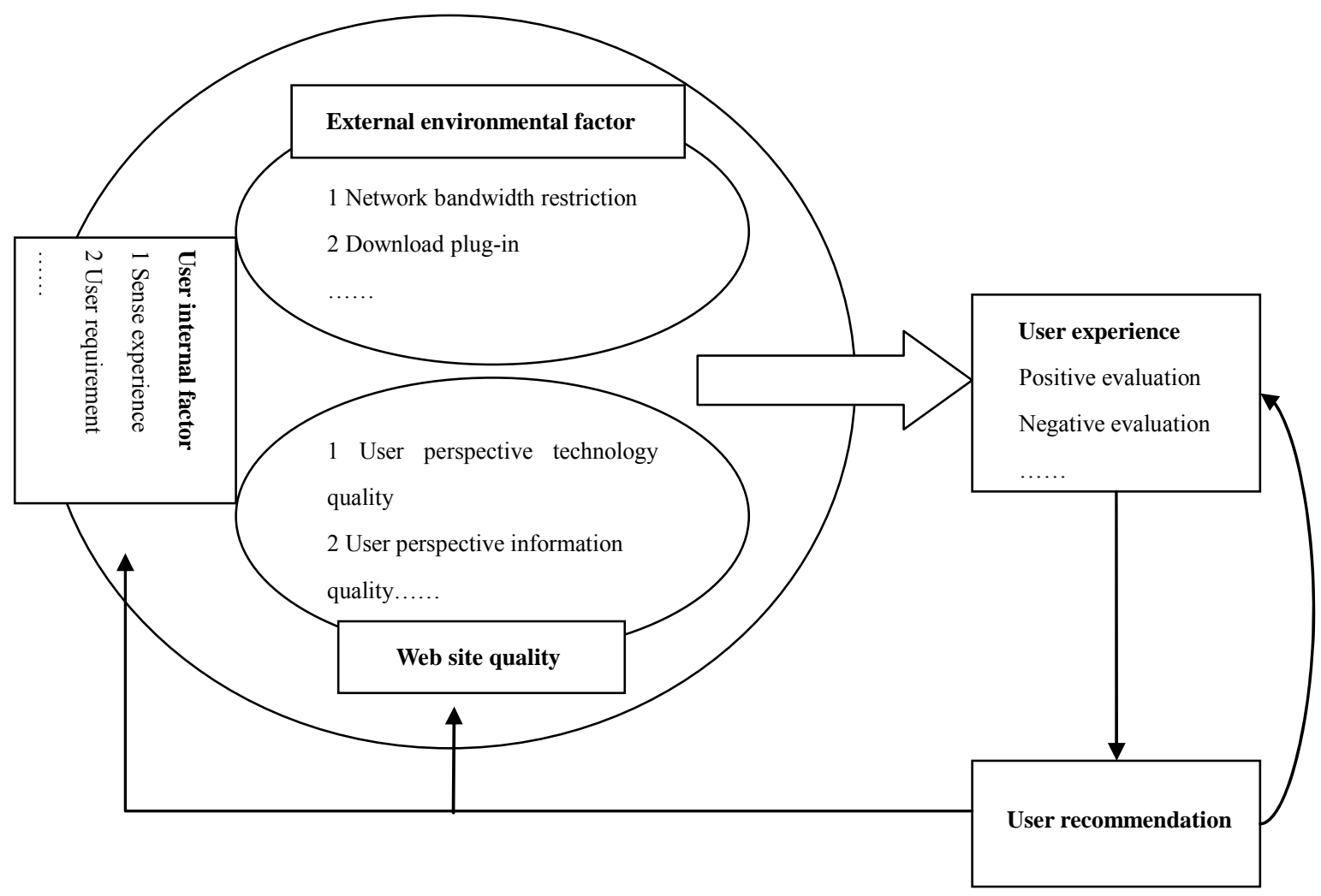

Figure 2. The model of influencing factors on Web 3D user experience.

ity and recommendation, they commonly affect the user experience through grounded theory. How to improve the four factors to enhance user experience and allow user to generate positive evaluation for the site?

\subsection{External Environmental Factors}

External environmental factors: 1) Users need to download the plug-ins. The plug-in is so-called real-time rendering engine, the real-time rendering technology is the key technology on Web 3D. Before watching the site, we must download the plug-ins, or we can't watch it. Different developers choose different tools according to special condition. That is to say, the browser doesn't fix the appropriate plug-ins for us beforehand, so when we watch different Web 3D site, we must download different plug-ins. It generally takes several minutes to wait for downloading, as that time, the users maybe lost patience and form the feeling of discontent. The users generally are reluctant to download some strange plug-ins, especially many of those, users may form a negative evaluation on experience. 2) Network bandwidth restriction. Before watching the site, users need download the Web 3D models. To keep the graphics' accuracy, the document may be very large, if the bandwidth is not enough, users will take a long time to wait, impacting the user experience. The two points always bring bad user ex- perience, so we can't ignore them. In the survey, most users mentioned these problems. The designer of online Guangdong used advanced technology to solve the plug-in problem-3Dii, 3D interactive integration software, which is based on Flash. As we all know, Flash technology is quite mature currently, forming a set of common standards. You can watch the Web 3D without having to download special plug-in, because the browser has fixed some flash plug-ins. For instance, the Shanghai World Expo recommends the Virtools, but its anticipating fix-rate is only $0.01 \%$, which nearly can be neglected. It is why the click rate on online Guangdong is able to list in forefront. From the Table 4, we can see the advantages of 3Dii technology.

\subsection{Web Site Quality}

Web 3D site quality includes the following: 1) User perceived technical quality. Strong interactive experience brings more actual experience. Users desire to communicate with virtual tourists and guides on scene, and that can meet their social attributes. Therefore, if the developers increase aesthetic feeling and the 3D scene's accuracy, etc., when building Web 3D site, bring high expectation to user at technical level, which will help users generate positive evaluation and increase experience. 2) User perceived information quality. The selected infor- 
Table 4. The advantage of 3Dii.

\begin{tabular}{|c|c|c|c|}
\hline & 3Dii & Flash & Traditional VR plug-in technology \\
\hline 3D show based on Web & $\begin{array}{l}\text { Include Flash--3D engine, support } \\
\text { sundry 3D style, such as 3Dmax, } \\
\text { Google Sketch up and so on }\end{array}$ & $\begin{array}{l}\text { Most browsers support Flash, } \\
\text { but it do not include engine } \\
\text { need in 3D development }\end{array}$ & $\begin{array}{l}\text { Need to download special plug-in, } \\
\text { and hard to use }\end{array}$ \\
\hline Integrate other Web service & $\begin{array}{l}\text { Using ESB and Mashup, fast achieve } \\
\text { the integration of other Web service } \\
\text { and application }\end{array}$ & $\begin{array}{l}\text { Can not integrate other } \\
\text { application, need complicated } \\
\text { second-development process }\end{array}$ & $\begin{array}{l}\text { Can not integrate other } \\
\text { application, need complicated } \\
\text { second-development process }\end{array}$ \\
\hline Response speed & $\begin{array}{l}\text { The response speed is so quick, with } \\
\text { using active rendering technology } \\
\text { and data compression technology }\end{array}$ & The response speed is slow & The response speed is slow \\
\hline
\end{tabular}

mation on Web 3D site is not only covers full, but also haves a clear mainline. That helps users clearly know the subject the site wants to express. The information shouldn't be piled, and should be unique, meaningful and thoughtful and attract people. The interface of online Guangdong was designed beautifully. At the beginning of experience, virtual reality simulation let users feel pleasure, immersed, expectant. But, the three themesGuangdong Culture, Modern Guangdong and Green Guangdong, don't have significant differences on interface design. With the passage of experience time, users may feel boring. On information, online Guangdong illustrates the characteristics introduction about Guangdong, and has three clear-cut themes, letting people know clearly and learn a great deal of unheard knowledge or understand deeply about Guangdong Culture, the whole site has a strong historic and cultural character.

\subsection{User Internal Factors}

User internal factors include the following: 1) Sense experience: Sense experience mainly meets users' visual and auditory pleasure. In the fast living, young people are more likely to complete several things simultaneously, it may bring them the sense of accomplishment. Just quietly watching the screen for a long time, you will feel boring, while the beautiful music can satisfy users' audition and mobilize users' other sense, so that users form a pleasant mood. Importantly, users have higher demand on the selection of music, they are eager to hear the music which is matched with the picture. The visual pleasure mainly refers to the video on Web 3D. The video can enrich the content of the site, and they complement each other. Thus, Web developers can compensate the defect that the virtual reality is not enough vivid through the polished video and audio technology, so that, the user experience will be improved. 2) User requirement. User wants to access a broader knowledge through the site to satisfy his or her desire for knowledge and touch them on the history. The online Guangdong does not make background music, which does not impact user's audition, results in user feels a little boring. If adding beautiful music, this helps people form good mood, and this can make people immerse in experience and neglect the technology itself, so that the site can remedy some defects. In addition, the online Guangdong's videos have rich contents, improving the single reading form, and they meet users' needs of accessing knowledge, attract many users' attention.

\subsection{User Recommendation}

User recommendation and user experience influence each other. After the experience, user will form positive or negative evaluation, and give his or her recommendation. It maybe changes the negative experience into positive experience, when developers adopt a part of practical recommendations to improve the site after screening. Even though some recommendations are not adopted, the feedback satisfies users' psychological needs of being highly regarded, causing the users' evaluations more positive. For example, some users suggest the local dialect can be used in video to introduce this place, increasing site features, if this recommendation is adopted by designer, people maybe feel site more real and cordial. Therefore, enhancing the communication with users and listening to their voice are the most important factors to form good user experience.

\section{Conclusions}

The influencing factors on Web 3D User Experience are studied for online pavilion of Shanghai World Expo with questionnaire and in-depth interview and grounded theory method. We get the four influencing factors and study case for the online Guangdong pavilion of Shanghai World Expo to improve the process of transformation original, wonderful, and creative ideas into Web 3D more perfective in the view of user experience. It is just beginning for our research. In our understanding, other areas needing further investigation may be in the following: integration of game development into computer science curricula in conceptual age [8], assessing creativity in Web 3D design, just as Hollywood, the creativity in Web 3D design is also key to success [9], deeper inves- 
tigation of corresponding factors in the model, how user experience on social agents forms and how user experience changes over time, the detail is illustrated in [10].

\section{Acknowledgments}

Thanks for helpful discussion with Prof. Hongbo $\mathrm{Xu}, \mathrm{Mr}$. Shaowu Zou, Dr. Xiao Xu, and Mr. Dejie Li etc.

\section{REFERENCES}

[1] B. J. Pine II and J. H. Gilmore, "Welcome to the Experience Economy," Harvard Business Review, July-August, 1998, p. 97.

[2] M. Agrawala, W. Li and F. Berthouzoz, "Design Principles for Visual Communication: How to Identify, Instantiate, and Evaluate Domain-Specific Design Principles for Creating more Effective Visualizations," Communications of the ACM, Vol. 54, No. 4, 2011, pp. 60-69.

[3] B. Schmitt and A. Simonson, "Market Aesthetics: The Strategic Management of Brands, Identity and Image," The Free Press, New York, 1997.

[4] E. L. Law, V. Roto, M. Hassenzahl, A. P. Vermeeren and J. Kort, "Understanding, Scoping and Defining User ExPerience: A Survey Approach,” Proceedings of CHI'09.
ACM, Boston, April 4-9 2009, pp. 719-728.

[5] M. Hassenzahl, "The Interplay of Beauty, Goodness, and Usability in Interactive Products," Human-Computer Interaction, Vol. 19, No. 4, 2004, pp. 319-349.

[6] J. Forlizzi and S. Ford, "The Building Blocks of Experience: An Early Framework for Interaction Designers," In D. Boyarski and W.A. Kellogg Eds., Processes, Practices, Methods, and Techniques, Proceedings of the 3rd conference on Designing Interactive Systems, Brooklyn, August 17-19, 2000 ACM, pp. 419-423

[7] J. Corbin, A. Strauss, "A Basics of Qualitative Research: Techniques and Procedures for Developing Grounded Theory," Sage, London, 1990.

[8] M. Zyda, "Computer Science in the Conceptual Age," Communications of the ACM, Vol. 52, No. 12, 2009, pp. 66-72. doi:10.1145/1610252.1610272

[9] K. D. Elsbach and R. M. Kramer, "Assessing Creativity in Hollywood Pitch Meetings: Evidence for a DualProcess Model of Creativity Judgments," The Academy of Management Journal, Vol. 46, No. 3, 2003, pp. 283-301. doi: $10.2307 / 30040623$

[10] J. Liu, X. H. Sun, "What Shapes User Experience?" Advances in Psychological Science, Vol. 19, No. 1, 2011, pp. 94-106. 